\title{
An Interdisciplinary Concept of Activity
}

\author{
Andy Blunden
}

\section{Independent Social Research Network Melbourne, Australia}

E-mail: ablunden@mira.net

\begin{abstract}
It is suggested that if Cultural-Historical Activity Theory (CHAT) is to fulfil its potential as an approach to cultural and historical science in general, then an interdisciplinary concept of activity is needed. Such a concept of activity would provide a common foundation for all the human sciences, underpinning concepts of, for example, state and social movement equally as, for example, learning and personality. For this is needed a clear conception of the 'unit of analysis' of activity, i.e., of what constitutes 'an activity', and a clear distinction between the unit of analysis and the substance, i.e., ultimate reality underlying all the human sciences: artifactmediated joint activity.

It is claimed that the concept of 'project collaboration' - the interaction between two or more persons in pursuit of a common objective - forms such a unit of activity, the single 'molecule' in terms of which both sociological and psychological phenomena can be theorised. It is suggested that such a clarification of the notion of activity allows us to see how individual actions and societal activities mutually constitute one another and are each construed in the light of the other.
\end{abstract}

\section{Introduction}

Vasily Davydov was right when he said that activity is an 'interdisciplinary' concept:

I always argue that the problem of activity and the concept of activity are interdisciplinary by nature. There should be specified philosophical, sociological, culturological, psychological and physiological aspects here. That is why the issue of activity is not necessarily connected with psychology as a profession. It is connected at present because in the course of our history activity turned out to be the thing on which our prominent psychologists focused their attention as early as in the Soviet Union days. Things just turned out this way (Davydov, 1999: 50, emphasis added).

The objective of this paper is to take up Davydov's observation and investigate what is needed for one and the same concept of activity to be useful both in the resolution of problems associated with individuals and their relations, and those associated with societal entities and their relations. Such a concept would provide a rational basis for psychology (including education, organizational theory, and so on) to ap- 
propriate concepts from sciences concerned with societal phenomena (economics, cultural studies, political science, and so on) and vice versa, and contribute to overcoming the individual/society dichotomy. Interdisciplinary work is commonly organized through the cooperation of different specialists who each use specialist theories and concepts, but communicate with one another in the lingua franca. But Davydov is right in suggesting that 'activity' can provide a common theoretical foundation across disciplinary boundaries. What is proposed is not a theory of everything, but rather concepts which facilitate disciplines critically appropriating insights from other disciplines.

And surely, when Marx spoke about activity (Tätigkeit) in "Theses on Feuerbach" (1975a) he meant precisely an interdisciplinary concept of activity, and not a concept limited to the solution of problems of individuals and small groups. In fact defining practice as the coincidence of changing circumstances and activity, he says that "All mysteries which lead theory to mysticism find their rational solution in human practice and in the comprehension of this practice." All mysteries, not just psychological mysteries. In the oft-quoted early pages of "The German Ideology," (1975b) he went so far as to claim that the "real premises' for his work would be 'the real individuals, their activity and the material conditions under which they live, both those which they find already existing and those produced by their activity' (1975b: 31). So defined, this project remains before us to this day.

Because of the 'historical accident' referred to by Davydov, the concept of 'activity' 'stayed out of politics' (Sawchuk \& Stetsenko 2008), so to speak, and came to be linked specifically to psychology. Despite the efforts of Activity Theorists, the concept as it has been developed is inadequate beyond the domain of what Hegel referred to as 'subjective spirit' self-contained activity amongst a finite group of individuals. Such a science is inadequate for grasping the connection with societal phenomena, because Activity Theory has had to uncritically borrow its conceptions of societal entities from other sciences; but it is these entities which constitute the content of the psyche in modern societies. According to Activity Theory, an activity is a system of actions in pursuit of some object. But in reality, the identity of such activities have been borrowed from other sciences, and fitted into activity theory by means of arbitrarily defining suitable 'objects'. For example, a spinner is participating in the activity whose object is yarn, although the worker's goal is wages, and the employers' goal is profit. (Leontyev 2009)

In what follows we will review the general conception of activity, drawing upon the classic work of Leontyev, leading into consideration of how activity is conceived of as the substance of the human sciences. We will contrast this conception of activity as substance with the conception of a 'unit of analysis'. How these ideas are dealt with by three Russian writers whose work is canonical and frequently cited in the current literature will be considered, and reviewed briefly in relation to two problems of the social sciences: Marx's critique of political economy and the constitution of social subjects. We will then consider whether Engeström's response to the problems which have been identified, and the work of Michael Cole in bringing out the importance of context. We will then propose a conception of the 'unit of analysis' of activity which provides a foundation for both the human sciences and ethics.

The method of argument used here is immanent critique, the method, originated by Aristotle, developed by Hegel (1977) in his Phenomenology, and applied by Marx in his critique of political economy and by Vygotsky (1997) in his study of the Crisis in Psychology. Instead of standing outside of a theory and pointing out its failings relative to this outside position, immanent critique enters into the current of thinking itself, and follows the concept's 
own development. In making sense of the history of a concept, the critic is led to an objective conception of its crisis. This entails a line of argument marked by contradictions, rather than a series of smooth logical deductions - that is the whole point: to bring out the contradictions, and show how they are resolved in actuality. For this approach, science is not the function of an individual, but is a social process, advancing through crisis and contradiction.

\section{The General Conception of "Activity"}

The idea of 'Activity Theory' is associated with the name of Aleksei Nikolaevich Leontyev (1904-1979, here "Leontyev"), so let us begin with his definition of activity.

Leontyev defines activity through the relation between subject and object. For Leontyev, the subject is any living thing, inclusive of whatever form of sensation and consciousness that the organism has. The object is something in the subject's environment which represents to the organism the satisfaction of a need. Activity is what mediates between subject and object.

This approach has the advantage of allowing the origins of consciousness to be traced from non-human organic matter. Human life is distinguished by the fact that the objects of activity and the needs which the objects satisfy them are no longer natural objects and biological drives, but rather artifacts and needs which are themselves products of human activity. Human life is thus conceived as a system of needs and the means of their satisfaction.

According to Leontyev, activity is the processes by which a person's actual life in the objective world is realized - what they are doing (Tätigkeit), as opposed to the nervous, physiological processes that realize this activity within the organism, including mental processes (Leontyev, 2009). The subject-activity- object relationship exists wherever a living thing, as 'subject', has a need which lies outside of itself, satisfaction of which is the object of the subject's activity, activity which is stimulated by the object.

The categories of subject, object and activity are mutually constitutive. Leontyev's concept of subject is like Kant's in being associated with an individual organism, but differs from Kant's, in that it embraces all living organisms, not just human beings. Because human needs are products of social life and are invariably satisfied by the products of social life, the object is always an artifact. In this sense then, activity is always mediated by artifacts, but 'artifact' is here understood in terms of the object of activity.

Alexander Meshcheryakov explains how a child born deaf-blind first comes to experience a human need:

Any deaf-blind child has a number of basic natural wants (to eat, excrete and protect himself). Initially these wants do not in themselves constitute true needs in the psychological sense of that word. They do not exist as human needs in the strict sense, they cannot as yet provide the motive force behind purposeful behavior, and for this reason no human behavior is to be observed in the early stages. These wants become true needs only after they start to be objectivized and satisfied through human methods involving tools and implements (Meshcheryakov 2009).

Possibly the first human activity the child born deaf-blind may learn is eating with a spoon. The spoon is the bearer of the whole history of humanity which lies behind the production of the spoon, adapted for use in a certain way and no other. The deaf-blind child comes to need a spoon, and using a spoon may be their first human act, and the first element of human consciousness.

Leontyev is at pains to point out that:

The expression 'objectless activity' is devoid of any meaning. Activity may seem 
objectless, but scientific investigation of activity necessarily requires discovering its object (Leontyev, 1978).

and continues:

Thus, the object of activity is twofold: first, in its independent existence as subordinating to itself and transforming the activity of the subject; second, as an image of the object, as a product of its property of psychological reflection that is realized as an activity of the subject and cannot exist otherwise (Leontyev, 1978).

As a special case of the more general category of natural, object-oriented activity, human activity is adapted to and reflects the objective properties and connections of its objects, but these are themselves human products. The foundation of psychology is the capacity of the human organism to reflect the properties of the objects of its activity.

So it is human needs which form the structure of activity for Leontyev. Remember that by human needs we do not mean the biological drives which underlie the activity of lower animals, but rather the human needs and the artifacts in which they are objectified, the objects which are themselves products of social activity.

Human activity is further characterized by the fact that it is social activity meeting social, or collective needs; the needs of individuals are met only thanks to the meeting of social needs. As a result of division of labor, we have a separation between the goals of an individual's action and the objective motive of the activity, which is deemed to be the meeting of some human (i.e., social) need.

The motive of an activity (such as production of yarn) is not translated directly into individuals' goals (such as earning a wage). The problem of forming individuals' goals so that the individuals' actions are rearticulated to constitute activities which meet social needs is a problem of the social organization of labor.
The goal of the individual's action arises only thanks to the representation of the activity through the mediation of social relations.

This is Leontyev's general conception of object-oriented activity. Not limited even to human life, activity is ubiquitous. Activity is neither the object nor a method of research, but rather is a general conception of the nature of the underlying reality, what is called the 'premises' of a science, or its 'substance'.

\section{The Substances, or Premises of a Science}

If we are to gain a clear idea of the problem of 'unit of analysis' then it is important to clarify the different notion of 'substance'. The Stanford Encyclopedia of Philosophy explains 'substance' as follows:

the substances in a given philosophical system are those things which, according to that system, are the foundational or fundamental entities of reality (Robinson, 2004).

Thus, the substances, or 'premises' of a science are the conception the researcher has of the ultimate reality underlying the universe of phenomena with which the science is concerned. The same notion of the substance will underlie a whole number of distinct enquiries and sciences, within the broad scope of a world view. For example, naïve realism presumes the existence of matter existing independently of human activity, and obedient to natural laws which are to be investigated. It is not a question of whether this 'belief' is true or well-founded (undoubtedly it is), but simply that the whole idea of natural science is to describe the world of Nature, beyond all labor processes. This meaning of the word 'substance' has flowed over into the natural language. For Kantian skepticism, science deals with a subjective domain of appearances, manifesting things-inthemselves which are beyond perception; so the objects of possible experience are the sub- 
stance, while 'matter' and 'things-inthemselves' are deemed not to be legitimate objects for science. For Hegel, the premises were Spirit (Geist), which he described as "the nature of human beings en masse," (Hegel 1952 \$264) but which he conceived of as pure thought; for Hegel even Nature was a manifestation of Spirit. But no writer in the CHAT tradition has broached the issue of substance. Outside the domain of psychology and small group interactions, CHAT theorists generally are generally naïve realists in respect to formations outside the domain under study. Such an approach does not give a means of critically appropriating from other disciplines.

Marx however was clear. For Marx, the 'real premises' were "the real individuals, their activity and the material conditions under which they live" (1975b: 31). 'Activity' is to be taken as an interdisciplinary concept, because for Marxists it is part of the premises for all science, including even the natural sciences. The way in which activity functions for natural science became clear with the advent of quantum physics and relativity, in which the relevant entities cannot be described independently of the human activities through which they are made objects of experience. For the natural scientist, the wave-particle nonetheless remains matter in the philosophical sense of the word. Natural scientists can accommodate recourse to the language of activity as a method of description of Nature, while maintaining matter as the substance. But for the human sciences, activity is crucial, for the objects of human life are both constituted and perceived by activity, and this is the key aspect of activity which an interdisciplinary concept of activity must address. Notice also that for Marx, activity was not the sole substance, for there can be no activity without individual human beings and a material world which includes the material products of human labor.

To be clear, we cannot talk of a 'science of activity' since this would amount to a sci- ence of everything, like a 'science of matter'. In investigating the basis for an 'interdisciplinary' concept of activity, the aim is (1) to construct a richer definition of activity as a premise for both psychological and sociological sciences, and (2) focus on those problems lying on the boundary between psychology and sociology. To define this relation a little more precisely, we should note that psychology takes as given the forms of social practice and the artifacts constituted by the culture within which an individual psyche develops. On the other hand, the sociological sciences effectively take as given individual psyches which are adapted to and reproduce the culture in which they are active. But the viability of these acts of abstraction has its limits, just as the viability of natural science's abstraction of natural entities from activity has its limits. We need a conception of activity which is equally adapted to the problem of the constitution of forms of practice as to the problem of the constitution of the psyche. Leontyev's general description described above fails to provide such a conception.

In summary, if we are to formulate an interdisciplinary concept of activity, then following Marx, we must:

(1) take the individuals and the material conditions, i.e., the constellation of material artifacts, along with activity, as our premises.

(2) form a clear conception of the essen-

tial problem of the mutual constitution of social life and individual consciousness.

Central to both problems is the conception of what constitutes 'an activity', that is, of what constitutes a unit of social life, from the standpoint of Activity Theory. The objects of social life are institutions, cultures, discourses, norms, and so on. Activity Theory suggests that these objects are constituted by activity, but what, from the standpoint of activity theory is the basic unit, the 'unit of analysis', from which we can elaborate the constitution of the objects of social science through activity? 


\section{The "unit of analysis"}

Central to formulating the foundations of any science is the idea of 'unit of analysis', as it is called in the CHAT tradition, following Vygotsky. This is the requirement to form a concept of the class of problems to be investigated. It is what Marx meant in Preface to first edition of Capital, when, following Goethe (1996), he referred to the commodity relation as the 'cell':

But in bourgeois society, the commodityform of the product of labor - or value-form of the commodity - is the economic cell-form (Marx 1996).

Note that Marx derived the whole range of phenomena of bourgeois society from the commodity relation, despite the fact that exchange of commodities is a relatively rare occurrence in developed capitalism (Ilyenkov 1960): invariably commodities are purchased and sold for money. Marx derived money as a special limiting case of commodity; but if instead, he had begun with money, then he would have been quite unable to disclose the 'mystery' of capital, because, by starting with such a developed conception as 'money', he would have skipped over the very processes of differentiation and development which make the relations of capital comprehensible. Exchange of commodities is the most primitive relation which, when further developed, unfolds into purchase and sale, contract, the market, the accumulation of capital, wage-labor, interest and so on and so forth.

It is the same idea as what Hegel called the Notion or conception of a thing, as he explained in relation to the foundations of the science of right, for example:

The science of right ... must develop the idea, which is the reason of an object, out of the conception. It is the same thing to say that it must regard the peculiar internal development of the thing itself (Hegel 1952, §2).
In the "Philosophy of Right," Hegel dealt not just with right, but with the entire range of problems which arise with the creation of a modern nation-state, on the basis that all the social and political phenomena of the modern nation state grow out of the notion of private property, which he calls 'abstract right' - the cell or unit of analysis for what Hegel called 'objective spirit'. That is, while spirit remained the substance for Hegel, for an analysis of modern society, the unit of analysis, according to Hegel, was a right, at root, simply private property. In the same way, the Logic is made up of three sciences: Ontology, the science of Being, Essence, the science of Reflection and the science of the Concept; the Philosophy of Nature is the science of Space. Thus Hegel's Encyclopaedia was a 'circle of circles'.

Marx and Hegel spent considerable labor to identify, not the most typical or even the simplest unit of the complex they were studying, but the most primitive or archetypal relation, the relation which, once it comes into being, through its own process of development, sets in train the series of transformations which produces the whole complex. Exchange of commodities or the recognition of private property are each a kind of 'virus' which, once established, spreads and replicates itself and transforms the whole organism.

The definition of a 'unit of analysis' allows a science to be elaborated rationally (as opposed to empirically), and sheds light on the class of problems which prompted it. The type of problems opened up by an interdisciplinary conception of activity are analogous to what Gadamer (2005) called the 'hermeneutic circle': each word in a text is interpreted in the light of it being part of a text of certain genre; but conversely, the text is deemed of that genre only through the meaning given to each of the constituent words. Likewise, the meaning of each individual action is derived from an understanding of the whole activity of which it is a part, but conversely, social phenomena are 
constituted only in and through the meaning given to individual actions. In general, individuals uncritically accept for they appear to be, all the states, social classes, institutions and so on, they meet with; psychology tends to follow individuals in this uncritical acceptance of the ontology of social life. Meanwhile conversely, the social sciences tend to accept human nature as it is, rather than seeing that individual consciousness is constituted by the forms of activity of which individuals are a part.

As we have seen from Leontyev's general conception of activity, any social entity which performs some social function may be counted as 'an activity' for the purpose of psychology. But while a state, for example, is indeed constituted by activity, is 'activity' a fruitful way of approaching the science of the state? That is, does the idea of the state as a system of activity meeting some specific social need (security maybe?) provide a sounds basis for a science of the state? Can we simply replace the various social formations which need to be understood in their own terms, with a 'needs' so that it can be 'an activity'?

An interdisciplinary theory of activity will surely be in its element in dealing with those problems where the aspect of the constitution of a social phenomenon or entity by the actions of individuals has a nearly equal weight with the aspect of the actions of individuals being determined by the relevant social formation of which they are a part. That is, problems where the interdependence of individual actions (psychology) and forms of social practice is most prominent. Such problems span psychology and sociology, and it is on such problems that an interdisciplinary concept of activity ought to be able to shed some light.

An interdisciplinary science of activity requires a definite conception of "an activity," that is to say, a unit of analysis which represents just one unit of the totality of social life. How can we analyze activity as the social life of human beings? What is a 'unit' of social life? And what are the types of activity and according to what criteria do we differentiate them? Unless we can determine the units and types of activity from the definition we make of an activity, then we will obliged to categorize activity according to arbitrary and extraneous criteria. This would lead to an uncritical description of society.

Although activity forms an underlying reality for all the sciences, it has only been Marxist psychology and Marx's political economy which have explicitly taken up the concept. But these two sciences which have emerged from common origins are quite foreign to one another at any but the most superficial level. A minimal requirement for an interdisciplinary concept of activity would be that one and the same conception of 'an activity' should be consistent with both cultural-historical psychology and Marx's critique of political economy, or at least make the relation between the two transparent.

In forming a 'unit of analysis', and in line with what Marx had to say on this topic, and what is in any case self-evident, activity has to be taken together with the real human beings active in that activity, and the actual constellation of material culture constituted in that activity. Amongst other things, this excludes the possibility of beginning with hypothetical situations belonging to a mythological past or imputing to nature relations and laws which are to be later rediscovered in human activity: it means beginning with human beings of the kind we find before us today, and whose propensities we wish to disclose.

In the light of a study of the development of the idea of 'unit of analysis' under various names, in Goethe, Hegel, Marx and Vygotsky, described by this author elsewhere (Blunden in press), the indispensable characteristics of the unit of analysis are as follows:

(1) It is the conception of a singular, indivisible thing (not a collection or combination) (Hegel 2009 §86), but it is typically a particu- 
lar genus of some universal (such as word meaning, commodity relation, private property, conditioned reflex).

If it is a collection or combination, this simply means that we have not started at the real beginning, having already uncritically accepted as given, the component concepts and relations. As a particular, it may be or not be (for example a reflex may be conditioned or not, i.e., unconditional) and this particularization points to a process of genesis, an inner movement and tension.

(2) It exhibits the essential properties of a class of more developed phenomena.

The point is to discover which thing exhibits the essential properties of a class of phenomena. The discovery of the cell is always the outcome of a search for the essential relation behind a persistent series of problems. As a cell, it is not a typical relation, but rather the most primitive of its type, a prototype (Hegel 2009 §163). The unit of analysis poses the key problems which can be examined without presuppositions.

(3) It is itself an existent phenomenon (not a principle or axiom or hypothetical force or such like non-observable), in Goethe's term, an Urphänomen (Goethe 1996).

A science can only base itself on something real and empirically given. But the existent thing must be captured as a concept because it is the starting point both for a real development and for the development of understanding. For example, if we understand a child's 'social situation of development' simply as a collection of factors capable of influencing the prospects for a child's development we have nothing more than an excuse to do some statistics. On the other hand, when we grasp the situation as a predicament, a trap from which the child must emancipate herself (Borozhov 2004), then we have what is both a concept and an existent reality. Vygotsky's (1997: 318) discussion of Pavlov's study of salivation in dogs confirms that Vygotsky used this same conception of 'unit of analysis'.

The general conception of activity described earlier is insufficient as a 'unit of analysis'. 'Activity' is inherently indeterminate, because it is everything. A 'unit of analysis' on the other hand, is determinate, as simple and determinate as it is possible to be. 'Activity' is not a singular thing but a quasi-infinite class of things, a substance, the conception of the ultimate reality for a science. As a unit of analysis for a science we need some determinate genus of activity, an elementary unit of social life.

In what follows I will review of the approach of L. S. Vygotsky, A. Meshcheryakov, A. N. Leontyev, Yrjö Engeström and Michael Cole, writers whose work has been widely cited in this tradition, with the aim of making an immanent critique, i.e., tracing problems in the notion of activity brought out by criticism made within this current of thought.

\section{Vygotsky's Concept of Activity}

Although Activity Theory is associated with the name of Leontyev rather than Vygotsky, the concept originated in psychology with Vygotsky. The key aspects of Vygotsky's concept of activity are to be seen in the scenario in which a novice (or experimental subject) is trying complete some difficult task, and an adept (or researcher) assists the novice complete the action by offering them an artifact to use in solving the problem. This scenario is represented in the 'double stimulation' experiment (Vygotsky 1978). By capturing the psychological function of a novice just as it first develops in the process of instruction, Vygotsky sheds a unique light on the essential nature of human psychology. In order to successfully complete a task, the subject must use an artifact, and this artifact is not simply discovered by the subject, but is introduced and demonstrated by the other, who acts as a bearer of the culture. The novice thus completes the action by means of 
collaboration with another in the use of an artifact. Similar scenarios appear in other areas of Vygotsky's later work.

Vygotsky always focused his scientific work on interactions between individuals, rather than using representations of societal phenomena and institutions abstracted from their constitution in specific forms of activity, but this does not detract from the significance of his work for understanding societal activities. After all, societal institutions exist only in and through individual actions and interactions between individuals.

In the double-stimulation relationship, two people collaborate in one completing a task set by an other, using an artifact introduced by the other. The artifact is a cultural-historical product. In this scenario, all the essential elements of a notion of activity are encapsulated because the artifact may be a product of the wider society, and the other carries the knowledge of how to use it. So this is not just a localized relationship between two individuals, but is nonetheless a cultural-historical formation.

Vygotsky (1997b) also introduced the idea of a 'psychological tool' - an external stimulus the use of which introduces a new internal stimulus into an existing stimulusreaction reflex. The psychological tool begins as a material object - a word, a symbol, a tool or even a body part - which a person learns to use in collaboration with another person; the external stimulus is gradually transformed into an internal stimulus, so that the activitystructure of the external world of artifacts is internalized in the form of the structure of consciousness and the subject becomes able to perform the relevant task without the use of an external stimulus.

Vygotsky famously spoke of 'wordmeaning' as a 'unit of analysis', but this author agrees with V. P. Zinchenko (1985) that "one can consider tool-mediated action as being very close to meaning as unit of analysis" so word- meaning can be taken as a special case of toolmediated collaborative action.

Some confusion has arisen around the claim that Vygotsky defined 'word meaning' as a unit of analysis of consciousness. Vygotsky's position is put forward unambiguously in the first chapter of Vygotsky's definitive "Thinking and Speech" as follows:

By unit we mean a product of analysis which, unlike elements, retains all the basic properties of the whole and which cannot be further divided without losing them. ... The true unit of biological analysis is the living cell, possessing the basic properties of the living organism.

What is the unit of verbal thought that meets these requirements? We believe that it can be found in the internal aspect of the word, in word meaning. ...

... it is in word meaning that thought and speech unite into verbal thought. In meaning, then, the answers to our questions about the relationship between thought and speech can be found. (Vygotsky 1997b)

So Vygotsky saw word meaning as the unit for the analysis of the relation between thinking and speaking. In the concluding words of "Thinking and Speech" he says:

Thought and language ... are the key to the nature of human consciousness. Words play a central part not only in the development of thought but in the historical growth of consciousness as a whole. A word is a microcosm of human consciousness. (Vygotsky 1997b)

The idea of 'microcosm' is a different concept again, the idea here being that exhaustively investigating the relation of thought and speech, will shed light on all problems of consciousness, because of the centrality of speech in human development, but it does not mean that word meaning is a unit of analysis for consciousness. Such a claim would be absurd, since clearly it is practice, i.e., individual hu- 
man beings, material conditions and activity, not words which is the foundation of consciousness. The problem of language is indeed key, but far from exhausting the problem of consciousness, it is the most developed form of behavior. The rest of Vygotsky's work testifies to the fact that the shared use of cultural tools of any kind was Vygotsky's unit of analysis.

All the essential aspects of the concept of activity are present in this concept of Vygotsky's. It has been subject to criticism however. Leontyev correctly pointed out that the meaning and motives of a person's action cannot be found either within the individual, their use of an artifact or their relationship with the collaborator. For this reason, Leontyev made a distinction between the individual's action, and the social activity of which it is a part and which gives it meaning; the goal of action is not the same as the motive of the activity of which the action is a part.

The idea is that over history, and the evolution of humankind, action and activity which are initially identical, became separated from one another. Originally needs were satisfied immediately, but with the deferral of satisfaction and the growth of a division of labor there developed a labor process, means of production and culture generally. This distinction between action with its immediate goals, and activity with its social motivation, is not touched upon by Vygotsky. This is the criticism of Vygotsky which laid the basis for what became known as Activity Theory.

\section{Meshcheryakov's Work}

Alexander Meshcheryakov was a student of Vygotsky's colleague A. R. Luria, and an associate of Feliks Mikhailov and Evald Ilyenkov. In his development of Vygotsky's concept of activity, he was able to respond in practice to criticisms of Vygotsky's concept.

Meshcheryakov (2009) developed Vygotsky's conception of learning through collabora- tion in his work in the education of deaf-blind children. A child who is deaf and blind from infancy will generally not develop a fully human consciousness without scientific intervention. This work gave Meshcheryakov's staff the opportunity to bring consciousness into being where it did not previously exist. The teacher is not just 'experimenting' on the child, but assisting the child in achieving something it needs to achieve.

In Meshcheryakov's scenario, the teacher manually helps the novice complete a task using an artifact taken from the cultural life of society, and then gradually withdraws that assistance, in such a way that the novice is able to take over the teacher's actions and complete the task autonomously.

In using a spoon to eat, the child does not just satisfy its immediate need for nourishment, but by mastering practical-sensuous actions with the spoon, forms an internal image which contributes to a reconstruction of the whole universe of social conventions and practices with which the spoon and its shape is associated. Meshcheryakov takes us through the process whereby his students learn, step by step, the skills of self-care, play and communicating with others, learn the lay-out of their home, their neighbourhood and the activities which go on in the various buildings, learn a daily timetable, a calendar, the important national holidays and their meaning, learn to grow and prepare food, learn to travel by public transport and explore the country and so on and so forth; in other words, to reconstruct in their own consciousness and activity the entire sweep of the culture of their society.

Meshcheryakov calls the unit of analysis 'shared object activity' (Meshcheryakov 2009: 294).

A kind of vicious circle develops: in order to know how to act with the tool the child has to know it, and in order to know the tool it is essential that the child act with it. The vicious circle is broken when the adult begins to teach 
the child to act with the tool in the process of satisfying its needs. This instruction is only possible in the form of joint object action shared between the adult and the child. (Meshcheryakov 2009)

Human culture is built into the artifacts a person uses and the actions of those with whom they are collaborating. Neither Meshcheryakov nor Vygotsky, however, went on from these ideas of interpersonal collaboration to develop an approach to understanding societal phenomena on a broader scale, that is to say, a social theory. And this is the problem which Leontyev tackled.

\section{Leontyev's Anatomy and Taxonomy of Activity}

Leontyev never claimed to have identified a 'unit of analysis' for activity, and always used the word "unit" in inverted commas (AA Leontyev 2006), but he did construct an anatomy of activity based on the fact that every activity has an object (Leontyev 1978). Whatever its limitations, Leontyev's effort to develop a theory of activity made the important advance over Vygotsky's theory in defining activity as a societal entity, beyond the domain of the individual's immediate relations and actions, providing objective motives for the individual's actions which differed from the subjective goals of the individual's actions. Something of this kind is necessary if we are to develop an interdisciplinary concept of activity which 'connects' the domain of psychology and the domain of the social sciences.

Each activity is defined by its motive, but in the sense of an 'objective' or social function, the attainment of a socially determined object and satisfaction of some social need rather than a narrowly psychological entity. But such an 'objective motive' is reflected in the consciousness of individuals in such a way as to motivate their actions, actions which as mentioned above, differ from the activity as a result of the development of a social labor process. The object thus has a dual existence, being the objective means of satisfaction of a need, and the socially constructed image of it which serves as the motivation for a social labor process, which may or may not prove adequate to its object and which may or may not be present in the consciousness of an individual. An activity for Leontyev is thus a 'social function', in this subjective/objective sense.

Activities are realized by individual $a c$ tions which are controlled by individuals, each oriented towards some goal. An activity is realized by many actions pursuant to different goals, but while the goals differ from the motive of the activity, the activity has no material existence separately from the actions through which it is realized. A goal, such as "Go to point A," must be kept in the individual's mind if they are to take the appropriate action, but the goal does not provide its own inherent motive. Further, it is not assumed that the individual has an objectively true conception of the motive behind the activity to which their action contributes; all that is necessary is that for one reason or another they pursue an appropriate goal, and the divers goals pursued by different individuals objectively add up to furtherance of the activity. On the other hand, this understanding of an activity and action means that there can be no immanent definition of an activity on the basis of its constituent goals. The activity cannot be defined solely in terms of what everyone is striving to do. So what constitutes 'an activity' can only be determined either from an $o b$ server standpoint, outside of activity, or by those who manage society and the various social functions. This scientific, objectivist aspect of Leontyev's approach is the cost of bridging the gulf between psychology and sociology.

Operations are the means by which actions are realized according to conditions, and may not be consciously or purposively selected or controlled. Actions become 'internalized' in 
being transformed into operations, that is, they become 'second nature'.

The archetypal activity for Leontyev is a collective hunt by a tribal group, in which different individuals cooperate through a traditional division of labor, pursuing different goals (beating or trapping) which contribute to realization of the social product, which is then distributed according to social norms and rules, so that the needs and expectations of each individual are met. The actions are carried out using socially developed operations which have become 'second nature' to the individual, of which they are only conscious when something 'goes wrong'.

The concepts of operation and action and some concept of activity form an adequate basis for a psychology, and it is not my intention to criticize the concepts of operation and action. The question with which I am concerned here is only the adequacy of Leontyev's notion of 'an activity', as a connecting link between psychology and the phenomena of broader social life.

The importance of having a critical perspective in relation to activity, as a societal entity realized by individual actions, is that it is not generally possible to lift an action out of its connection with the activity it is realizing and which, in a given culture, invest the action with social meaning. We will return to this problem below when we consider the cross-cultural research of Michael Cole.

Leontyev's idea is that in the social field there are various activities; each of these activities is deemed to be meeting some social need, performing some function within the community's construction of its needs. There are types of activity according to different types of social need. Individuals are motivated to participate in these activities, but what goals they are motivated to pursue and what motivates them to pursue those goals, are open questions. The individuals' goals are generated in the social division of labor and their 'objective motives' originate in social life somewhere beyond the horizons of their subjective field of action. An individual may be motivated by dreams of glory to go to war, or motivated by fear of poverty to become an operative and contribute to the accumulation of capital. That is all open.

Over and above the artifact-mediated actions already highlighted in relation to Vygotsky's treatment, the core of Leontyev's conception of activity is the production and satisfaction of needs. This story is all about needs:

... we always must deal with specific activities, each of which answers a definite need of the subject [i.e., the individual], is directed toward an object of this need, is extinguished as a result of its satisfaction, and is produced again, perhaps in other, altogether changed conditions.

... The main thing that distinguishes one activity from another, however, is the difference of their objects. It is exactly the object of an activity that gives it a determined direction. ... The main thing is that behind activity there should always be a need, that it should always answer one need or another. (Leontyev 1978)

This conception is dependent on an uncritical vision of society as a division of labor either rationally planned or economically and culturally evolved to meet the social needs of its citizens. Such conceptions are compatible only with the myth of the socialist state or the image of a primitive tribal society. It is most certainly not compatible with bourgeois society or at any rate, with Marx's vision of bourgeois society as set out in Capital and elsewhere. But the starting point for a science cannot be some other world, whether of the primeval past or the utopian future. The starting point for science must be, as Marx insisted, the "real activity of individuals" which can be "verified in a purely empirical way."

We will now move to consider Leontyev's concept of activity in relation to two problems of social science for which Marxism has developed authoritative models: political economy and the constitution of social subjects. 


\section{Leontyev's Theory of Activity and Marx's Political Economy}

Marx repeatedly insists that the object of all labor subsumed under capital is the expansion of capital, but in Activity Theory, the object of an activity is always the meeting of a human need, albeit a socially produced collective need. The idea that the object of the market and capital accumulation is the satisfaction of human needs is precisely what Marx was arguing against. For example, in Chapter 11 of Capital, we read:

If we consider the process of production from the point of view of the simple laborprocess, the worker is related to the means of production, not in their quality as capital, but as being the mere means and material of his own purposeful productive activity... But it is different as soon as we view the production process as a process of valorization ... the lifeprocess of capital consists solely in its own motion as self-valorizing value (Marx 1996).

Leontyev's conception of activity as being made up of 'systems of activity' each answering to a definite need of the citizens suggests a theory of history in which social relations evolve somewhat like an ecological system. Leontyev's theory is a kind of functionalism.

Now it could be argued with some merit that this characterization of Leontyev's theory is a parody: Leontyev allows that the motives of social activities are generated and meaningful only socially. But if we allow that in the last analysis, the objects of activities are not human needs, but some other product of social history, then we are no further forward: either the notion of the object of an activity is tautological or the notion of a human need is devoid of meaning. The supposed 'object' of an activity is just an ideal reification of that activity. Insofar as Leontyev's concept of an activity is compatible with how any social theory constructs its objects, it seems that it can add nothing to it.
In fact, Leontyev's Activity Theory does not seem to find any significant psychological difference between the Soviet Union, capitalist America or Saudi Arabia.

The unit of the social life of capital is the company (Connell 1977), not a functional branch of industry. For Marx, capital is a 'quasi-subject'. Capital is an activity which sets goals and actions for individuals and underlies representations people form of the motives of their actions, and its units are units of capital, companies. But capital cannot be understood as answering a definite need of the individual, and directed toward an object of this need. Of course, capital produces use-values, and the advocates of the market take that as the beginning and end of the matter, but according to Marx the object of labor in bourgeois society is the production of exchange value and the accumulation of surplus value. The production of usevalues is a means to an end, not the object of activity itself.

The structure of capital, divided into companies (in the broad sense), internally structures activity by means of a flow of funds downwards supports a confluent command structure, subject to the capital market. All labor subsumed under capital can be divided into units and analyzed easily according to the understanding of capital as a form of activity. Human needs are a secondary matter in the dynamics of capital. Other organizations modeled on capitalist enterprises function internally in the same way, and it cannot be presumed that the formal aims of the organization (e.g. a public service) is the effective object of all actions in the organization as every nodal point in the distribution of funds creates new (bureaucratic) interests. Not only may goals be at odds with motives; actions may be at odds with activities!

Now, even today, the relations of capital do not exhaust social life; there are other forms of activity that provide different motivations other than expansion of capital, but nothing in Leontyev's notion of activity seems to offer an 
opening for such a distinction, other than the conception of capital as a distortion or internal contradiction within an otherwise healthy labor process. This is not an adequate standpoint.

Leontyev (2009) talks about the problems for his theory arising from the contradiction between use value and exchange value, but he only goes so far as to point to distortions that the market introduces into cultural evolution. He points out that a doctor must desire that his patients are ill, because it is by curing their illness that he earns a living. He points out that norms of distribution may lead to unfair remuneration for some participants in the social labor. He talks about the psychological effect of alienation. But he does not see these observations as calling into question the fundamental idea that the object of an activity (including wage labor) is the meeting of an objective, social need. At the strictly psychological level, this does not seem to pose a problem: a wage laborer indeed pursues a goal useful to the employer with the idea that her own needs will be met as a by-product in distribution of the social product by means of wages, and doubtless also believes that her work meets a social need, not just the profit of the employer.

That people manage to live despite capitalism is not simply because their needs are met as a by-product of capital accumulation. Were social life to be totally subsumed under capital, then not only would the social conditions for human life be destroyed but the natural conditions for human life would be extinguished as well. But it is surely self-evident that a psychology which is to shed light on the psychology of modern capitalist society must recognise that this society is a capitalist society, not contingently, but essentially, with a specifically capitalist array of character and psychology.

So as a theory of psychology Leontyev's activity theory still works, just so long as the content of 'activity' is not taken too seriously. But what then does activity theory add to Vygotsky's original formulation?

\section{Groups as a Model of Sociality}

On the face of it, the problem of identity and the constitution of social subjects, would seem amenable to an Activity Theory approach. Social subjects are the formal or informal, collective self-conscious actors on the terrain of social life, mediating between system-wide phenomena and lives of individuals. The formation of social subjects was a central concern of Hegel, and Marx dealt with it in writings such as "The 18th Brumaire" and there is a vast modern literature on group dynamics, identity and other related topics.

Leontyev's model of activity theory retains the Kantian conception of the individual subject, whilst the activities in which individuals participate remain objective functions or structures, so the idea of collective subjectivity does not fit easily in Leontyev's theory. A solution which many writers, both Marxist and nonMarxist, have adopted is to put in the position of the individual subject "an individual or group." That is, the problem of the social character of human agency is elided by the supposition that a group may act in the same way as an individual, but without considering any additional problems about how a 'group' is constituted, what is meant by 'group membership' or how an individual comes to accept the actions of a particular group and not another as their own.

For example, Vladimir Lektorsky, who is renowned for his work on the subject-object relation in the Activity Theory tradition, says:

Activity cannot exist without a subject. But the initial form of a subject is no ego, but a subject of collective activity (e.g., a group, a community, a team). The individual subjective world, individual consciousness, ego are not something given (as philosophers in the 17th and 18th centuries thought), but the result of the development and transformations of collective activity or practice. (Lektorsky 1999: 107) 
There is no doubt that social subjects of this kind exist and the concept of corporate or collective subject has an important role in cultural and historical analysis. However, group membership is only one limited mode of subjectivity. Still more limited is 'membership' of abstract general groups such as race or gender.

But more importantly, the posing of group membership solves nothing in relation to the problem of the sociality of individual action. In fact, the existence of social groups and how they are constituted by individuals is an additional problem for Activity Theory over and above the objects of activity, as well as the problem of how a group acts, when in reality actions are only ever executed by individuals. Rather than being a solution to the problem of membership of society, the idea of membership of group simply sets up an infinite regress much like the homunculus sets up an infinite regress in the other direction. The concept of group membership is also a particularly poor representation of sociality in relation to modern society. Membership of a team or committee is one relatively marginal part of social life.

This 'lumpy' conception of subjectivity, being either an individual subject or a collective subject, far from solving the problem of the social construction of consciousness, altogether misses the point: how is the relation between an individual person and institutions like nation, market, industry, etc., or group, to be mediated?. For example, in the classic example of a hunting group used by Leontyev to explain the structure of activity, the question of how the group of individuals come to be constituted as a group is elided by supposing them to be members of a primitive tribal group. How does that work for members of modern society who do not belong to 'tribes'?

How an individual thinks and acts to one degree or another as part of a group is a question which needs to be answered, not presupposed by activity theory. Activity theory can and must shed light on identity, interpersonal relationships such as solidarity, loyalty, friendship, ethical commitment, respect for law, pursuit of science, religious identity, ability to cooperate with others, the acquisition of cultural competences and so on. Societies are not homogeneous; the relation between the individual and the people as a whole is one of the most essential problems of the human sciences. Born into society, and pursuing culturally-historically produced ends with culturally-historically produced means, the individual is participating in cultural-historical activity, not as a Kantian 'individual subject', but as a 'social subject', without any implication of being a 'member of a group'.

\section{Yrjö Engeström's 'root model of human activity'}

Yrjö Engeström tackled a lot of the problems in Leontyev's model with his comprehensive schema of nested triangles. Engeström starts with the natural model of the activity of social creatures, in which an individual's relationship to their environment is mediated by their community. This makes in fact a threeway relationship of mutual mediation, as the community's relationship with its environment is mediated by individuals and the individuals' relationship with their community is mediated by the environment.

The specifically human form of life then develops through the mediation of each of these three relationships:

- The individuals' relationship with their environment opens up as the direct relationship with nature is mediated by emergent tool use and tool making underlying a system of production mediating between needs and their satisfaction.

- The relationship of the entire community to the means satisfying its needs opens up with the direct relationship being replaced by a division of labor with a system of distribution of the products of labor. 
- The direct relationship of the individual to the group gives way to the emergence of larger and more complex communities and social relationships mediated by norms, rules and traditions, including the exchange of products on the market.

The combination of production, distribution and exchange are then mediated by a system of social consumption of the products of labor. Thus, we have Engeström's (1987) famous expanding triangle of triangles. The relationship between the (Kantian, individual) subject and its object (the means of satisfying the subject's needs) is now subject to multiple lines of mediation. Each implementation of this schema produces an outcome which is a changed relationship of all the factors, and each of the mediating links contains contradictions, the mediation of which generate further lines of development.

In the editorial introduction to "Perspectives on Activity Theory" (1999) of which Engeström is co-author, he says that a 'strong candidate' for a unit of analysis of Activity Theory is "object-oriented, collective and culturally mediated human activity, or activity system." This definition is a fair representation of the state of Activity Theory up till now.

In his classic work (1987), Engeström traced conceptions of the 'unit of analysis' used by a series of writers in the Russian CHAT tradition, and went on to specify four criteria for what he calls a "viable root model of human activity":

First, activity must be pictured in its simplest, genetically original structural form, as the smallest unit that still preserves the essential unity and quality behind any complex activity. Second, activity must be analyzable in its dynamics and transformations, in its evolution and historical change. No static or eternal models will do. Third, activity must be analyzable as a contextual or ecological phenomenon. The models will have to concentrate on systemic relations between the individual and the outside world. Fourth, specifically human activity must be analyzable as culturally mediated phenomenon. No dyadic organism-environment models will suffice (1987).

The first of the above criteria clearly indicates that Engeström is talking about a 'unit of analysis', though he never actually makes this claim, and indeed denies it. Nonetheless, the way the concept is deployed, it takes the place of a unit of analysis. It cannot be a unit of analysis however. Altogether, Engeström's model represents relationships between individual (subject), object, outcome, community, environment, social rules, instruments of production, division of labor, production, distribution, exchange and consumption. Engeström calls this the 'root model' for activity theory on the basis of the above criteria.

Even if we assume that production, distribution, exchange and consumption are $d e$ rivative rather than essential concepts, and we take 'outcome' as a reproduction of the object, we are still left with seven distinct concepts subject, object, community, environment, social rules, instruments of production and division of labor - which have to be derived before we have any 'unit of analysis'. But if the ultimate reality we are dealing with is activity, then every one of these concepts is derivative of the concept of activity. For example, 'subject' is one of the seven concepts which are presupposed in the conception of activity; but what is the nature of the subject? And how is a 'community' constituted if not by activity? Answers to these questions should be outcomes of a theory of activity, and cannot be its presuppositions.

The idea of pairs or triplets of concepts which are mutually constitutive, being a differentiated unity, has a long pedigree, but a set of seven mutually constitutive concepts is not really tenable, and Engeström surely doesn't mean it that way. 
Engeström's claim rests on the idea of the initial natural relationship of individualcommunity-environment 'expanding' through the intervention of mediating elements. This would make activity the coincidence of three processes: tool-making, law-making and labor organization. So activity is derivative from these concepts. It is a plausible conception, similar to Hegel's schema of the differentiation of production and consumption mediated by labor, and used to theorise the emergence of Spirit in his 1802-03 system, but it is entirely speculative. It has no empirical content. The only unity tying the set of concepts together as whole is the thesis that at some time in the past things happened this way. Such a speculation cannot be the premise for a science or its starting point.

To make a start with a science we have to have a concept of what it is that we are investigating and the possibility of observing it. But here at the very least we have seven entities, whose conceptions are posited as preliminary to the science of activity. The argument seems to be a proof that one cannot have a unit of analysis for Activity Theory, inasmuch as the root model which is "the smallest unit that still preserves the essential unity and quality behind any complex activity" is already a composite.

Whether it is called a 'root model' or a 'unit of analysis', Engeström's 'expanding triangle' is an impressive schema of social life, but it is not the foundation of a science, in the sense that Goethe, Hegel, Marx and Vygotsky envisaged. Engeström has given us an elegant general schema for various components of social life, but he has not given us a conception of any of those components or of activity itself.

\section{Michael Cole and cultural context}

Michael Cole agrees that the unit of analysis for Activity Theory is 'joint artifactmediated activity' but he points to some important nuances in what constitutes 'an activity' and the relation of actions and artifacts to the activity in which they are subsumed.

Firstly, Cole showed (in press) that activities cannot be 'modeled' by action systems lifted out of the cultural contexts to which they are indigenous and dropped into another cultural context. Cross cultural researchers had underestimated, according to Cole's findings, the extent to which the presuppositions of standard interviewing and test procedures are implicit in the use of certain types of artifact, styles of speech and so on. This meant for example, that standard psychological tests used as part of scientific activity, would fail when implemented with people belonging to a different culture to which the practice of scientific research is foreign. For example, people who were quite unfamiliar with being asked questions, the answers to which were obvious and already known to the questioner, solely in order to test their intelligence or whatever, would respond to such questions in ways that bore no relation to the test design. The ways in which questions were construed by the subjects on one hand, and by the experimenters, on the other hand, were quite different.

Secondly, Cole found (1997) that psychological work with experimental subjects could only succeed to the extent that both the researcher and the experimental subject shared a common aim (even if they had different motives). This could happen if an adult subject was part of a culture where scientific experimentation was widely understood and supported, but in many cases it could only be achieved by the researcher focusing on achieving something that the experimental subject wanted to achieve, in the hope that scientific insights would come as a by-product of the subject doing what she wanted to do anyway. For example, in order to effectively study a learning process, it was necessary to actually help someone learn something they really wanted to learn.

Generally speaking the actions and artifacts used in the scenario have to be indigenous 
to the culture of the experimental subject and the scenario must be either itself a normal part of the subject's culture, or so constructed that the way in which it is construed within the subject culture is transparent.

Under these conditions it is possible for the two parties to share a common 'project'. Otherwise ambiguity, misunderstanding and failures of communication prevail. Where subjects are not committed to a common project, one and the same action or artifact, for example an interview question, could figure in two different activities. This is the relevance of the 'hermeneutic circle': each action is interpreted by a subject on the basis of a presumption of the activity or project of which it is a part, but a project can only be perceived through the actions by which it is instantiated. This is how cross-cultural misunderstandings occur.

Much of Cole's research went to the fact that meaning is context-dependent, but if we were to rest at this point, then the possibility of a unit of analysis is ruled out, for 'context' is an open ended totality: where do you draw the boundary around what is relevant to context? But Cole's research went beyond the impossibility of meaning being retained in the transfer from one cultural context to another. Under appropriate conditions, an experimenter could carry out a test with a subject of a different culture, provided that the actions of both parties belong to a common project.

\section{Projects}

Like 'object', 'project' represents the teleological aspect of social life, people striving for something. Project is broader than object, because it includes both the end and the means, the norms through which an object is pursued within a given culture, over some period of time, with shared expectations about the meaning of the actions used. The means and ends are not distinct components of the project because, as Hegel (2009) demonstrated, means and ends mutually constitute one another and are ultimately identical.

'Project' differs from 'joint mediated activity' because it is a unit and not a substance; a project is 'an activity', a 'unit' of activity: pursuing shared aims according to certain common norms, over some period of time. Participation in joint mediated activity cannot be made sense of until we understand what project each participant construes the actions to be a part of, and how, if the different subjects are pursuing different projects, their respective projects relate to one another.

A project mediates collaborative activity, but it is not an artifact. All activity is artifactmediated, but people can cooperate in a project by pursuing the common aim even if they are not in direct communication. The use of artifacts remains a part of collaborative projects, but the key mediator is the project itself, however it is represented. Cultural differences such as language affect collaboration in a project, but what is fundamental is not cultural difference or commonality, but the project's common aims and norms.

Cole's work demonstrated that the specificity of an activity, its distinctness, as for example, being indigenous to a certain national culture, penetrates every aspect of a person's motivation, relationship to other people and understanding of actions and artifacts used in a scenario. Within a given culture, actions and artifacts are construed in a particular way according to the project that they are taken to be a part of. These findings bring us to the conception of a unit of analysis for activity that we are looking for.

\section{Towards a Unit of Analysis for an Interdisciplinary Activity Theory}

Societal phenomena, such as states, markets, social mores and institutions, which exist beyond the bounds of the immediate interactions amongst a group of individuals, neverthe- 
less exist only in and through the actions and experiences of individuals and the artifacts that they use, carrying with them shared or overlapping meanings. A hermeneutic circle operates in constituting both the societal phenomena and the consciousness of participating individuals which extends beyond the bounds one-on-one interaction. The problem cannot be resolved by naturalizing societal phenomena so that they can be taken out of the hermeneutic circle and treated as givens.

In the foregoing review of efforts to form a conception of activity, it seems that attempts to incorporate 'supra-individual' aspects of society such as social division of labor, norms and rules, systems of production and distribution, and so on, fail to provide the basis for a unit of analysis. The fact is that these societal phenomena exist for the individual only through (1) the use of artifacts which originate and carry culturally determined meaning from outside the immediate setting of their use, and (2) the regularity of expectations and experiences of interaction with other individuals. Consequently, a unit of analysis for the study of activity must be based on ideas like that of Vygotsky and Meshcheryakov cited earlier, which take the collaborative actions of two individuals, with one using an artifact introduced by the other, as the basis for understanding activity. Such collaborative actions are always part of a common project shared by the collaborating individuals. Notions of social norms, division of labor, markets, and so on, must therefore be derived from their foundation in the artifact-mediated collaboration of individuals in common projects or 'project collaboration'.

To be clear, 'project collaboration' is not something different from activity, but simply a unit of activity, a unit of joint mediated activity. Social life is a tangle of interactions, both formal and informal, between individuals, both friends and strangers; what is being suggested is that 'projects' are the threads from which the fabric of social life is woven and may be analytically unstitched.

The scenarios we have considered have been limited to pair-wise collaboration, but the presence of an artifact is always implicitly the presence of a third or more parties to the collaboration, so it seems that the essentials of multi-sided collaboration (as in group dynamics) are contained in two-sided collaboration so long as it remains the case that the artifact mediating the interaction between the two parties comes from outside. Collaboration always implies that the individuals involved share not only a common object but a common project. According to the OED, a project is "a planned or proposed undertaking; a scheme, a proposal; a purpose, an objective. In business, science, etc., a collaborative enterprise, frequently involving research or design, that is carefully planned to achieve a particular aim" (OED 2008).

'A project' differs from 'an activity' understood à la Leontyev, as a system of actions directed towards a given socially defined object in several respects. Firstly, a project includes the individuals and all the artifacts and norms and rules indigenous to that project. A project is always directed towards some ideal. Projects need to be understood as historically articulated, and individual projects carry forward projects that may have a long history. In this sense the idea of project is subject-centered rather than object-centered. In "Theses on Feuerbach," Marx criticised "hitherto-existing materialism" for failing to conceive of practice "as human sensuous activity, ... subjectively." It is not at all the case that in developing "the active side" an objective, materialistic standpoint is compromised. Human practice is active; activity is not just passive attraction to an object, but active projection and pursuit of ideals.

In recent Hegel interpretation (Pinkard 1994) the word 'project' has been used as an interpretation of what Hegel called a 'formation of consciousness', that is, a self-conscious his- 
torical form of social practice. 'Project' carries the connotation of being extended in time beyond the actions of current participants and through historical time, and of being an ongoing bearer of meaning, identity, values and ethical convictions.

Relations between collaborators in a project are not necessarily symmetrical or egalitarian, but a shared commitment to the project is integral to the concept and the project itself is part of the relationship. Projects harbor a host of different kinds of relationship and interaction.

\section{Collaboration}

Projects include conflict as well as cooperation; collaboration implies that the participants argue over what should be done and how. That is, the relationship in which one person endeavours to prevent the other from doing something is just as essential as the situation in which both strive for the same outcome by the same means. Simple cooperation, in which conflict is avoided, perhaps by means of a division of labor or the adherence to rigid norms and rules of behavior, fails to capture the nature of the collaboration. A conflict always has a shared situation as its outcome, which is indicative of a notion of its irreducible co-production; were it not the case that both parties will have to share the outcome, there would be no basis for conflict. The outcome is always the resultant of at least two independent wills, and contains moments of both conflict and cooperation. In general, we can see cooperation (pursuing the same end using some division of labor, whether natural or artificial) and conflict (pursuit of mutually exclusive states of affairs) are special, limiting cases of collaboration.

Other important limiting cases of collaboration, are those relating to 'ownership' of the project: solidarity is where one subject voluntarily subordinates themself to the other's ends; 'cooption' is where one subject subsumes an- other under their own project. Other limiting cases hinge on attribution, for example, a jeweler has a technician make ring to their design, but is attributed as the maker.

Collaboration is an important way of conceiving of social bonds, because the project provides the mediation between subjects sharing a social bond, which are consolidated through the shared artifacts and actions used on a continuing basis to pursue the project. Selfevidently, collaboration provides an approach to the understanding of social subjects from a participant point of view. Shared artifacts and interacting actions is an important condition for the formation of social bonds, but without the existence of shared projects amongst a group of individuals, social bonds cannot develop. Collaboration also offers an important way of approaching the ethical analysis of social relations.

\section{Ethics and Collaboration}

Invariably any scientific project carries within it a commitment to certain ethical norms and concepts. Liberal economic theory bases itself on a conception of individual, rational agents which also forms the foundation of liberal ethics, for example, and discourse analysis must presume that participants ought to persuade one another with rational argument, even while knowing they don't. A human science which does not make its ethical commitments explicit is only deceiving itself.

The notion of collaboration not only provides a starting point for science, but is also normative, in the sense that when subjects work together, then they ought to share control over the project and share in its rewards, and in general they expect to, even if they don't. Collaboration thus provides a reference point for ethics. For example, if a group of people work together to complete a difficult journey, then each will expect to have a say on the chosen route and bear an equal share of privations, and so on. 
Different relationships may apply (e.g. a guide leads a group of tourists, or a military commander assumes leadership) but in such cases where different ethical norms apply, the actions are quite different in their psychological implications. The psychology of collaboration does not arise directly from the activity itself, but is refracted through the relevant ethical norms.

As we have already noted, individuals participate in project collaboration in a number of quite distinct ways; they may strive to achieve the project or they may strive to frustrate or modify the project, and there is nothing inherently unethical in conflict; in fact conflict is a normal part of collaboration on projects; shared projects are impossible without conflict and conflict is meaningless outside of shared projects.

While individuals may participate in a project in order to further its ideals and practices, they may alternatively, participate in the project with only the aim of receiving sidebenefits which are external to the project, rather than those inherent in the project itself. This is a distinction which Alasdair MacIntyre (1988) makes, as for example, when sports stars play only for the high monetary rewards rather than to further the practice of the sport in its own right. For example, the psychology of art changes dramatically when an artist ceases to pursue the aim of furthering art and begins to produce for the market. It is impossible to separate the psychology from the ethical norms. The same goes for wage-labor. Individuals may make decisions collectively, or either party may take a leading role in defining the project, or one may simply follow the lead of the other, or even participate solely in solidarity with the other. The psychology of participating in some project is significantly affected by the extent to which a person participates in the planning and direction of the project. There are normative questions in all these modifications of the paradigmatic collaborative relationships, each of which also have significant psychological implications.

The idea of collaboration is already important in social service industries. Doctors and patients collaborate in restoring the patient's well-being, and health service workers know that the psychology and well-being of a patient are dramatically affected by their equal participation in their own treatment. The classical therapeutic relationship corresponds to quite different psychology, because in such a case the project of achieving the patient's well-being is exclusively that of the therapist.

Every instance of collaboration in a project has characteristic problems - the doctor may regard herself as expert and fail to share decision-making with the patient, the architect may see the building as a monument to their art rather than a home for the owner, and so on. All these issues are psychological in their impact because they are also normative.

Vera John Steiner made an extensive study of well-known artistic and scientific collaborations, and proposed a 4-way typology as follows:

1. Distributed collaboration, which "takes place in casual settings and also in more organized contexts. These include conversations at conferences, in electronic discourse communities, and among artists who share a studio space. In these groups, participants exchange information and explore thoughts and opinions. Their roles are informal and voluntary."

2. Complementarity collaboration: "characterized by a division of labor based on complementary expertise, disciplinary knowledge, roles, and temperament. Participants negotiate their goals and strive for a common vision."

3. Family collaboration: "a mode of interaction in which roles are flexible or may change over time" (John Steiner 2000).

There is in fact a whole literature on collaboration, especially collaborative learning in which CHAT already plays a central role, as 
well as studies of work methods, group dynamics, sports psychology and so on, where Activity Theory is immediately applicable even without the problems raised by the issue of an interdisciplinary concept of activity. This is not new: what is proposed is that this rich field of work on collaboration can be extended to theorise societal phenomena.

It may be noted as an aside here that Activity Theory has hitherto taken division of labor as the norm of cooperation. Leontyev's scenario of the primitive hunting group with a division of labor between the beater and the trapper is prototypical. But the whole idea of the motives of actions diverging from the goals of actions rests on the idea of elaboration of a division of labor as the process constitutive of the human condition. But if division of labor is built into the foundations, then for example, the possibility of taking a critical attitude towards a hierarchy of expertise in therapeutic work is excluded, let alone the neo-liberal conception of learning as a customer-service provider relationship between student and teacher, or other neo-liberal conceptions of the same kind. Division of labor is a special, limiting case of collaboration, but the reverse is not true. The hypothetical historical narrative in which division of labor is elaborated by the introduction of difference into a formerly homogeneous, presumably infinite community, does not stand scrutiny. Division of labor can just as well be seen to have arisen by formerly remote communities establishing trading relationships with one another, as an outcome of collaboration.

Collaboration is well-established as a paradigm in the creative arts and in the sciences, where cross-media, cross-disciplinary and cross-sectoral collaboration is regarded of particular creative value. The ethics of collaboration is in distinct contrast to liberalism, which emphasises the concept of the individual as an autonomous agent and the archetypal relationship between agents is contract or exchange, rather than collaboration. These are forms of cooperation which are external rather than internal to subjectivity.

The point of these quite cursory remarks is to draw attention to the richness of the concept of 'project collaboration'. It is the fact that collaboration has a normative core for human beings that makes it so rich as a foundation for human science; and it is the fact that collaboration lies at the foundation of formation of the human form, phylogenetically, culturally and ontogenetically, that makes collaboration such a powerful notion for ethics.

In fact, from the standpoint of collaboration, the formation of collective subjects - nations, churches, social movements, companies, etc., etc. - is almost self-evident, as collective subjects are collaborative projects.

\section{Marx's Critique of Political Economy and Activity Theory}

It is now possible to establish the relationship between activity theory and Marx's critique of political economy. Whereas project collaboration is the prototypical, genuinely human relationship, capital springs from the relationship of exchange of labor. It is especially clear in Marx's very early work, "Comment on James Mill," (1975) that Marx saw the relationship of exchange of the products of labor as an essentially manipulative and corrupting relationship. This relationship has nonetheless come to be the dominant relationship in bourgeois society. Capital rests on a quite particular (de)formation of the relationship of project collaboration, in which each subject pursues their own end, but regards the other's labor instrumentally, simply as a means to their own end, and pursues their project by means of exchange of equivalents. Nevertheless: "the notion of human equality [can acquire] the fixity of a popular prejudice ... only in a society in which the great mass of the produce of labor takes the form of commodities" [Capital Chapter 1] (Marx 1996). 
The commodity relation leads to an $a b$ stract general logic in which the projects pursued by different subjects relate to each other only externally or quantitatively, rather than a concrete universal logic, which characterizes project collaboration. The division of labor which results from the subsumption of collaborative projects under capital, puts abstract general relationships in the dominant position, and these abstract general relationships penetrate deeper and deeper into consciousness, with the results being concentration of capital and fragmentation of social bonds, as Marx demonstrated in Capital and other works, such as The Communist Manifesto.

So in this view, Activity Theory and Marx's critique of political economy have compatible conceptions of social life and methodological principles. But what of the conclusions to be drawn about the nature of social life? Marx's critique of political economy points to the outcome of the growth of a specific kind of activity, namely production for exchange, leading to a labor process more and more, though never completely subsumed under capital.

The normal situation today is that collaboration is subsumed under the market, where workers collaborate inside capitalist enterprises. Recently, neoliberal restructuring of corporations has increasingly introduced market relations inside companies. On the other hand, in the 'third sector', exchange is subsumed under collaboration, when some participants earn a living and others contribute monetarily while contributing to a collaborative project. In any real situation, both types of relationship are present and contribute to the psychology of the participants. Although project collaboration is the norm of social life amongst human beings, modern capitalism is seeing an expansion of the market and its penetration of more and more spheres of activity. Nonetheless, exchange of commodities remains a special, limiting case of project collaboration.
There is also a third mode of cooperation, hierarchy. In this mode of cooperation, labor takes place within some kind of hierarchy. This may be the command structure within an organization, or a traditionally established hierarchy in which people act according to their station in life, in relations of traditional dependence. Alternatively, it may be bureaucratic or meritocratic hierarchy, such as the hierarchy of expertise that develops spontaneously even within voluntary groups, in therapeutic relationships or for example the relation between teacher and pupils.

That is, there are three broad types of cooperation: hierarchy, exchange and collaboration. From the standpoint of project collaboration being a unit of analysis for activity theory, hierarchical command and customer/service provider relations are understood as limit cases of collaboration. Each of these modes of cooperation carries with it normative as well as descriptive weight. In this view, the relations of capital constitute one of several domains of modern social life; labor not subsumed under capital may be organized along traditional lines (such as domestic labor within the family) or may be collaborative (such as in voluntary organizations). It is important to establish what is psychologically and sociologically specific about the relations of capital in modern society. Political conditions in the Soviet Union made these kinds of distinction impossible. Relations of domination and exploitation which arose from the market outside the USSR could be subject to criticism, but relations of domination which arose from noneconomic causes such as bureaucracy or gender were undertheorized.

We shall now return to the question raised earlier of a taxonomy of activity.

\section{Towards a Taxonomy of Activity}

At first we see that project collaboration constitutes the basic unit, the molecule of social 
life, presenting us a picture of millions and millions of transitory relations of conflict and cooperation between people sharing certain ends, in a certain division of power enjoying internal and externals benefits, and using certain artifacts and types of action to mediate their collaborative activity. Such projects appear and disappear, and are reproduced in new forms at different times and places, are nested one within another, whilst every person is engaged in a multiplicity of such relationships at any given time. How ought we to move from this complex picture of apparently chaotic activity? How can this microscopic unit of analysis for activity underpin a view of social life as a whole?

Categorization of the different types of activity and their scope has to be derived from the notion of project collaboration itself, its normative core and the differences which can be unfolded out of that core, as anticipated above. We have already seen that the distinctions between collaboration, hierarchical command and the market flow from the notion of project collaboration. Within capital, different companies constitute units of capital as indicated by the management structure erected on the basis of ownership of capital. Hierarchical and collaborative relations arise from tradition, legislation, custom and so on and are normatively transparent in their structure according to the structure of organizations, states, families and so on, although subject to many kinds of distortion. Aside from the taxonomy that flows from different forms of the collaborative relationship, further distinctions follow from the articulation of projects over various periods of time from momentary to historical. Social movements, nations, religious communities all constitute themselves as projects. The pursuit of an art or profession, is also constituted as a project, with practitioners striving to perfect the art, each generation standing on the shoulders of the generation before.
An finer grain of analysis of social life is given by concepts, realized in and through activity. In general concepts represent the sedimentation of past projects which have become objectified within the culture. When concepts first appear, they constitute projects, but in time, they become objectified and merge into the fabric of social life, the language and culture generally. Once a concept has become objectified, it ceases to have an independent life, but participates as an aspect of all subsequent projects. Some concepts however, not yet objectified, retain vitality, and constitute living, self-conscious projects.

Consciousness is therefore constituted by participation in a multiplicity of different projects and activity organized around a multiplicity of different more or less independent concepts, which represent the sediment of past projects. "The tradition of all dead generations weighs like an nightmare on the brains of the living" (Marx 1979).

\section{Conclusion}

Cultural-Historical Activity Theory may fulfil its potential as a contributor to a general cultural and historical science, by studying the psychology of collaboration, laying a foundation from which the various societal phenomena can be rendered in terms of the same unit of analysis: project collaboration. Just as the atom is the system for particle physics, but unit for molecular physics; project collaboration is the system for psychology, but the unit for social science. It is the point where a 'hermeneutic circle' operates in the mutual constitution of social life and psychology.

Because the notion of project collaboration has both normative and descriptive force, there is an internal tension within the concept which is well suited to the study of individual and social development. 


\section{References}

Blunden, A. (in press) "Vygotsky's Idea of Gestalt and its Origins," Theory and Psychology, University of Calgary, Thousand Oaks, CA: Sage.

Bozhovich, L. I. (2004) Developmental Phases of Personality formation (II), Journal of Russian and East European Psychology, vol. 42, no. 4, 2004: 55-70, Armonk, NY: M. E. Sharpe.

Cole, M. (1997) Cultural Psychology, a once and future discipline, Cambridge, MA: Harvard University Press.

Cole, M. et al (in press) Cross-Cultural Research in the Cultural Historical Activity Theory Tradition.

Connell R.W. (1977) Ruling Class Ruling Culture, Cambridge, UK: Cambridge University Press.

Davydov, V. (1999) "A New Approach to the Interpretation of Activity Structure and Content," in Activity Theory and Social Practice: Cultural-Historical Approaches, Edited by Chaiklin S., Hedegaard M. and Jensen U. J., Aarhus, Denmark: Aarhus UP.

Engeström, Y. (1987) "Learning by Expanding," Helsinki: Orienta-Konsultit.

Gadamer, Hans-Georg (2005 [1960]). Truth and Method, New York, NY: Continuum .Goethe, J. W. v. (1996) Goethe on Science. An Anthology of Goethe's Scientific Writings, Selected and introduced by Jeremy Naydler, Edinburgh, UK: Floris.

Habermas, J., (1992) Moral Consciousness and Communicative Action, Cambridge, MA: M.I.T. Press.

Hegel, G.W.F. (1979 [1804]) System of ethical life (1802/3) and First Philosophy of Spirit (1803-4), translated by T. M. Knox. New York: State University of New York Press.
Hegel, G.W.F. (1977 [1807]) The Phenomenology of Spirit, Preface, translated by A.V. Miller, Oxford, UK: Oxford University Press.

Hegel, G.W.F. (2009 [1830]) Hegel's Logic, Kettering, OH: Erythrós Press.

Hegel, G.W.F. (1952 [1822]) The Philosophy of Right, translated by T. M. Knox, Oxford, UK: Oxford University Press.

Heller, A. (1986) Beyond Justice, Oxford, UK: Basil Blackwell Ltd.

Ilyenkov, E (1960) The Dialectics of the Abstract and the Concrete in Marx's Capital, Moscow, USSR: Progress Publishers.

Kant, I. [1780] Metaphysical Elements of Ethics, http://www.marxists.org.

John Steiner, V. (2000) Creative Collaboration, Oxford UK: Oxford University Press.

Lektorsky, V.A. (1999) "Historical Change of the Notion of Activity: Philosophical Presuppositions," in Activity Theory and Social Practice: Cultural-Historical Approaches, Edited by Chaiklin S., Hedegaard M. and Jensen U. J., Aarhus, Denmark: Aarhus University Press.

Leontyev, A. A. (2006) "'Units' and Levels of Activity," Journal of Russian and East European Psychology, vol. 44, no. 3: 30-46, Armonk, NY: M. E. Sharpe.

Leontyev, A.N. (2009) "Activity and Consciousness," in The Development of Mind, Kettering, OH: Erythrós Press.

Leontyev, A.N. (1978) Activity, Consciousness, and Personality, New Jersey: Prentice-Hall.

MacIntyre, A. (1988) Whose Justice? Which Rationality? Notre Dame IN: University of Notre Dame Press.

Marx, K. (1975 [1843]) "Comments on James Mill," $M E C W$ v. 3, 211-228, London, UK: Lawrence \& Wishart. 
Marx, K. (1975a [1845]) "Theses on Feuerbach," $M E C W$ v. 5, 3-5, London, UK: Lawrence \& Wishart.

Marx, K. (1975b [1845]) "The German Ideology," $M E C W$ v. 5, 23-93, London, UK: Lawrence \& Wishart.

Marx, K. (1979 [1852]) "The Eighteenth Brumaire of Louis Bonaparte," MECW v. 11, 103, London, UK: Lawrence \& Wishart.

Marx, K. (1996 [1867]) "Capital," MECW v. 35, London, UK: Lawrence \& Wishart.

Mead, G. H. (1956 [1934]) George Herbert Mead On Social Psychology, Selected Papers, Edited and with an Introduction by Anselm Strauss, Chicago, IL: University of Chicago Press.

Meshcheryakov, A. (2009) Awakening to Life, Kettering, OH: Erythrós Press.

OED, Oxford English Dictionary Online, http://www.oed.com/, accessed September 2008.

Pinkard, T. (1994) Hegel's Phenomenology, Cambridge, UK: Cambridge University Press.

Robinson, H. (2004) Stanford Encyclopaedia of Philosophy, entry on "Substance," http://plato.stanford.edu/entries/substance/.

Sawchuk, P. \& Stetsenko, A. (2008) "Sociological Understandings of Conduct for a Noncanonical Activity Theory: Exploring Intersections and Complementarities," Mind Culture and Activity, 15: 339-360, Florence, $\mathrm{KY}$ : Routledge.

Vygotsky, L. S. (1997 [1927]) The Crisis in Psychology, in Collected Works of L. S. Vygotsky, vol. 3., New York, NY: Plenum Press.

Vygotsky, L. S. (1997a [1929]) The Fundamental Problems of Defectology, in Collected Works of L. S. Vygotsky, vol. 2., New York, NY: Plenum Press.
Vygotsky, L. S. (1997b [1934]) "Thinking and Speech," in Collected Works of L. S. Vygotsky, vol. 1. Plenum Press.

Vygotsky, L. S. (1978 [1930]) "Problems of Method," in Mind in Society, Cambridge, MA: Harvard University Press.

Zinchenko, V. P. (1985) "Vygotsky's ideas about units for the analysis of mind." In J. V. Wertsch (ed.) Culture, communication, and cognition: Vygotskian perspectives. Cambridge: Cambridge University Press: 94-118. 